ORIGINAL ARTICLE

\title{
Community football players' attitudes towards protective equipment-a pre-season measure
}

\author{
R A Braham, C F Finch, A McIntosh, P McCrory
}

Br J Sports Med 2004;38:426-430. doi: 10.1136/bjsm.2002.004051

See end of article for authors' affiliations

\section{Correspondence to:}

Correspondence to:
Professor Caroline F Finch, NSW Injury Risk Management Research Centre, University of New South Wales, Sydney, NSW 2052, Australia; c.finch@unsw.edu.au

Accepted 26 June 2003

\begin{abstract}
Background: The Australian football injury prevention project (AFIPP) was a randomised controlled trial examining the effects of protective equipment on injury rates in Australian Football.

Objective: To present the results of the AFIPP baseline survey of community football players' attitudes towards protective equipment.

Methods: Teams of players were recruited from the largest community football league in Victoria, Australia, during the 2001 playing season; 301 players were enrolled in the study and all were surveyed before the season began about their attitudes towards protective headgear and mouthguards.

Results: Almost three quarters of the players (73.6\%) reported wearing mouthguards during the previous playing season (year 2000) compared with only $2.1 \%$ wearing headgear. The most common reasons for not wearing headgear and mouthguards (in non-users) were: "I don't like wearing it" (headgear: 44.8\%; mouthguards: $30.6 \%$ ), and "It is too uncomfortable" (headgear: $40.7 \%$; mouthguards: $45.8 \%$ ).

Conclusions: The higher mouthguard usage reflects the favourable attitudes towards mouthguards by Australian football players generally. Similarly, the low headgear usage reflects the low acceptance of this form of protection in this sport. Further research should be directed towards establishing the reasons why players seem to believe that headgear plays a role in injury prevention yet few wear it.
\end{abstract}

$P$ ersonal protective equipment (PPE) is used to control injury risk, and its effectiveness has been investigated in many physical activities including bike riding, ${ }^{12}$ ice hockey, ${ }^{3}$ and rugby. ${ }^{4-6}$ In Australian football, many studies have documented a significant risk of head and neck injuries. ${ }^{7-10}$ In recognition of this, the National Health and Medical Research Council (the premier health authority in Australia) published a report emphasising the importance of preventing these injuries. ${ }^{11}$ This report recommended that future work should concentrate on improving protective headgear and mouthguards and adopting them for this sport.

Australian football is a contact sport involving two teams of 22 players, 18 of whom are on the field at any one time. The game is played on an oval field of 135 to 185 metres in length and 110 to 135 metres in width. ${ }^{12}$ There are four quarters of play, each lasting 25 minutes. At the end of each quarter, time is added on to make up for time lost through delays in play (such as when a player is injured and play is stopped). ${ }^{13}$ Players move the ball up the field by kicking, handballing, punching, running, marking, and knocking the ball towards their goal end.

Injury surveillance studies have shown that the most severe injuries to Australian football players, across all levels of play, tend to occur to the head/neck/dental regions, with an estimated annual medical cost of $\$ 15$ million. ${ }^{14}$ Recent studies have reported that concussion in amateur Australian football accounts for $3.1 \%$ of all injuries ${ }^{15}$; in elite Australian football the mean concussion incidence rate was 4 per 1000 player hours. ${ }^{7}$ A prospective study on injuries at the elite level of Australian football has reported an overall head/neck/ dental injury rate of 14.1/1000 player hours. ${ }^{10}$

There is inconclusive evidence supporting the relative value of headgear in Australian football for preventing or reducing the severity of head injuries. Although it is believed that headgear may reduce lacerations and soft tissue injuries, it is unclear whether it can prevent concussion. ${ }^{11}$ Overall, there have been very few studies examining headgear use, its effectiveness in football players of any code, and players' attitudes towards it. One of the few studies conducted on the effectiveness of headgear in under-15 rugby union football players $^{6}$ found that current headgear does not provide significant protection against concussion. The attitudes of junior rugby players towards headgear were also assessed ${ }^{16}$ and the primary reason identified for headgear use was safety. Players also cited receiving an injury as a motivator for wearing protective headgear. There have been no studies conducted in Australian football addressing the attitudes of players towards protective headgear.

Attitudes towards PPE can have an influential effect on the actual use of the equipment. Wearing protective equipment is a type of behaviour, and players' attitudes towards protective equipment will influence their behavioural practices. It is important to establish players' current behavioural knowledge about protective equipment before effective efforts to promote protective equipment can be developed.

The value of mouthguards for preventing injury has been widely researched and it is generally accepted that dentistfitted mouthguards are the most effective in reducing dental injuries in contact sports. ${ }^{17}{ }^{18}$ Among international rugby players, $96.7 \%$ believed that mouthguards reduced injuries in and around the mouth. ${ }^{17}{ }^{19}$ In Australian football, there is evidence for the widespread use of mouthguards during competition, although usage tends to be lower in training..$^{21}$

Barriers to the use of PPE include the attitudes and behaviours of the target population. On the one hand, it is important that people choose to wear PPE; on the other hand it is important that those who wear PPE are not doing so to cover up risk taking behaviours. A possible indicator of whether players will adapt their playing practices while wearing PPE is their attitude towards it. ${ }^{22}$ Attitudes towards PPE have been described in participants in several Australian

Abbreviations: AFIPP, Australian football injury prevention project; $\mathrm{PPE}$, personal protective equipment 
sports activities, including teenage cyclists, ${ }^{23}$ junior rugby players, ${ }^{16}$ and squash players. ${ }^{24}$ Factors associated with negative attitudes towards PPE use have been identified as restriction and discomfort, ${ }^{24}$ while factors associated with positive attitudes are injury prevention and previous injury. ${ }^{16}{ }^{24}$

Our primary aim in this paper is to present the results of a baseline survey of community Australian football players' attitudes towards PPE. The evidence shows that injuries exist in Australian football, and the way to reduce them is to introduce preventive measures. If these measures are used improperly and at inappropriate times, then there will be no reduction in injury rates. Published reports on the use of PPE are limited and there are very few relating to community level Australian football. Without knowledge about protective equipment habits of Australian football players, strategies for injury prevention and safety promotion are difficult to implement.

\section{METHODS}

The Australian football injury prevention project (AFIPP) was a randomised controlled trial to assess the effectiveness of protective equipment use (headgear and mouthguards) in community level Australian footballers. Nine clubs from the largest metropolitan football league in Australia volunteered a total of 23 teams to participate in the study. The recruitment process was such that clubs volunteered to participate in AFIPP before team randomisation to one of four intervention arms (headgear alone; mouthguard alone; headgear and mouthguard; and control). All players from the 23 teams were then invited to participate in the AFIPP. Individual players from each volunteering team were approached after team randomisation had taken place and were given the opportunity to participate in the study.

Recruitment for AFIPP took place during the 2001 preseason period (February to March). The pre-season is the two month period immediately before the regular season, when general fitness and skills are practiced. All players who agreed to participate in the AFIPP completed a 10 minute baseline survey at a prearranged time during a training session.

In all, 301 community level football players volunteered for AFIPP (response rate 63.5\%) and 100\% of these completed the pre-season survey. Two variants of the survey were administered, a junior and a senior, differing only in the demographic questions asked. The survey was based on previous ones concerning attitudes to protective equipment, ${ }^{16} 23212526$ and information from publications in the area of adult risk taking behaviour. ${ }^{27}$ As in another study, ${ }^{28}$ feedback was received from the general manager and the football operations manager at the Eastern Football League, and a final version was constructed. This final version was pilot tested.$^{29}$ The survey covered the following areas:

- Demographic information: date of birth, suburb of usual residence, and occupation and/or study status.

- Playing and injury history: head/neck/dental injury history within the last 12 months, years playing Australian football, and usual position played.

- Current use of PPE.

- General attitudes towards PPE.

The questionnaire consisted of multiple choice questions with set options, which were derived from the pilot questionnaire. An "other" option was included to allow for additional responses and these were coded at the time of data entry.

The survey included written statements with a five point Likert scale response ranging from "strongly agree" to "disagree strongly" or "always" to "never". An agreement score ( 1 to 5) was calculated for each statement, with a higher score allocated to the more positive responses. The sum of the five questions was obtained and the overall agreement score ranged from 5 to 25 . The players were also asked to provide the two most appropriate responses from a list of up to 13 options about their PPE behaviours. They were instructed to answer specific questions, depending on their reported PPE behaviours.

All data were double entered into SPSS version 11.0 and analysed using descriptive statistics. Approval for the project was obtained from both the Deakin University and the Monash University human research ethics committees.

\section{RESULTS}

The mean age of the surveyed population was 22.3 years (95\% confidence interval (CI), 21.6 to 22.9) and these players had an average playing history of 10.8 years ( 10.1 to 11.5 ). Almost $85 \%$ of these players had not experienced a head/ neck/dental injury within the past 12 months.

Table 1 presents the descriptive results of players' self reported PPE behaviours. Just under three quarters of players (73.6\%) wore a mouthguard sometimes during the 2000 season, while only $2.1 \%$ wore headgear. The majority of PPE was worn during games only, with few players reporting wearing it during both training and games.

Almost three quarters of players reported wearing mouthguards sometime during the season, and injury prevention and safety were the most common reasons for this behaviour. Only six players reported wearing headgear. Safety and protection for previous injury were the most common reasons given by these players.

The reasons players gave for not using headgear or mouthguards are shown in table 2, while table 3 lists the most important reasons given for considering the use of PPE.

Dislike and comfort were the most commonly reported reasons for not wearing protective headgear and mouthguards. However, injury and the influence of an authoritative person were noted as the most common personal reasons that would lead to a change in behaviour in headgear use. Injury prevention was the most common reason for change of behaviour in mouthguard use.

Players who did not wear protective headgear or mouthguards during the 2000 season were asked whether they would stop playing Australian football if either headgear or mouthguards were made compulsory. Although more players indicated that they would stop playing if headgear was made compulsory, the difference not was not significant (Pearson's $\left.\chi^{2}=0.157, p=0.692\right)$. A larger proportion of players reported

Table 1 Self reported protective equipment wearing rates in community level Australian football players $(n=301)$

\begin{tabular}{llll}
\hline $\begin{array}{l}\text { PPE use during } \\
\text { the } 2000 \text { season }\end{array}$ & $\begin{array}{l}\text { Number of } \\
\text { players }\end{array}$ & $\begin{array}{l}\text { Per cent of } \\
\text { players }\end{array}$ & $\mathbf{9 5 \%} \mathrm{Cl}$ \\
\hline $\begin{array}{l}\text { Mouthguards } \\
\text { Overall * }\end{array}$ & 203 & 73.6 & 67.5 to 79.6 \\
$\begin{array}{l}\text { Training only } \\
\text { Games only }\end{array}$ & 52 & 26.9 & 14.8 to 38.9 \\
Games and training & 120 & 62.2 & 53.5 to 70.8 \\
& 21 & 10.9 & 0 to 24.2 \\
Headgeart & & & \\
$\begin{array}{l}\text { Overall } \\
\text { Training only }\end{array}$ & 6 & 2.1 & 0 to 13.6 \\
$\begin{array}{l}\text { Games only } \\
\text { Games and training }\end{array}$ & 1 & 16.7 & 0 to 89.8 \\
lam & 1 & 66.7 & 20.5 to 100.0 \\
\hline
\end{tabular}

*10 players did not report when they used a mouthguard. †Percentages do not add to 100 because of rounding.

$\mathrm{Cl}$, confidence interval; PPE, personal protective equipment. 
Table 2 The most commonly stated reasons for not wearing protective equipment during the 2000 playing season* $^{*}$

\begin{tabular}{|c|c|c|}
\hline Reason for not using PPE & $\begin{array}{l}\text { Headgear } \\
(n=268)(\%)\end{array}$ & $\begin{array}{l}\text { Mouthguards } \\
(\mathrm{n}=72)(\%)\end{array}$ \\
\hline I don't like wearing it & 44.8 & 30.6 \\
\hline It is too uncomfortable & 40.7 & 45.8 \\
\hline They restrict my airflow & & 29.2 \\
\hline I cannot speak properly when I wear one & & 16.7 \\
\hline I don't need to & 17.2 & 12.5 \\
\hline They restrict my performance & & 12.5 \\
\hline It is too hot & 14.9 & \\
\hline I don't want to look stupid & 11.3 & \\
\hline $\begin{array}{l}\text { There is no rule making me wear it } \\
\text { I have never tried one/ / have never }\end{array}$ & 10.8 & \\
\hline considered it & 10.4 & \\
\hline I don't want it to affect how I play & 9.0 & \\
\hline Other reasons & 18.6 & 38.9 \\
\hline
\end{tabular}

*The percentages add to more than $100 \%$ because players were requested to provide two responses.

$\mathrm{PPE}$, personal protective equipment

that they would not stop playing football if mouthguards were made compulsory. Conversely, a higher percentage of players was undecided if they would continue playing football if headgear was made compulsory.

Five attitudinal statements were presented on both headgear and mouthguards, and players were asked to select the most appropriate response from a five point Likert scale. The results for headgear and mouthguards are given in table 4 . The average agreement score for headgear was 17.6 (95\% CI, 17.3 to 17.9) and for mouthguards, 19.1 (18.8 to 19.4).

Figure 1 shows players' beliefs about protective headgear and mouthguard use. Overall, more players believed that headgear should not be worn during training and games, irrespective of playing level. On the other hand, more players thought that it was necessary to wear mouthguards during games, regardless of level, but that it was not necessary to wear them during training.

\section{DISCUSSION}

This is the first paper to provide detailed information about community level Australian football players' attitudes towards both protective headgear and mouthguards. Our study recorded the attitudes of 301 football players from a community football league in metropolitan Victoria. Although a pilot study of attitudes towards protective equipment in community level Australian football has been conducted previously, ${ }^{29}$ that study focused only on headgear.

Our study found that almost three quarters of all players reported wearing mouthguards, but the majority of these did so only during games. In contrast, very few players reported wearing protective headgear. The behaviours and general beliefs of the players in this study were that mouthguards are necessary during games but not during training, irrespective of the level of competition; and that headgear is not necessary at any time. These findings are consistent with anecdotal evidence that headgear use in Australian football is uncommon, but that mouthguards are often used, at least during games. ${ }^{20} 21$

Discomfort appeared to be an important reason for the non-use of PPE. Players reported "it is too uncomfortable" and "I don't like wearing it" as the two most important reasons for not using either piece of equipment. In contrast, the most common reasons reported for wearing PPE were for injury prevention and safety. These attitudes are similar in other sports. While bicyclists ${ }^{23}$ found discomfort to be one of two major factors contributing to non-use, studies of attitudes towards PPE in rugby ${ }^{56}$ and squash ${ }^{24}$ reported
Table 3 The most commonly reported personal reasons that would motivate a non-user of headgear or a mouthguard to consider using them*

\begin{tabular}{lll}
\hline Influence on PPE use & $\begin{array}{l}\text { Headgear } \\
(\mathbf{n = 2 7 6 )}(\%)\end{array}$ & $\begin{array}{l}\text { Mouthguard } \\
(\mathbf{n}=\mathbf{7 9})(\%)\end{array}$ \\
\hline If I had an injury & 67.0 & 46.8 \\
If I was made to by my club/school & 31.5 & 12.7 \\
If it prevented injury & 26.1 & 48.1 \\
If it was affordable to buy & & 15.2 \\
If it made me play better & 19.6 & 12.7 \\
If I wanted to be safe & 15.6 & \\
If my insurance company required & & \\
me to wear it & 12.3 & 12.7 \\
If I was a participant in the AFIPP & & 11.4 \\
If I was made to by my coach/parents & 10.5 & 13.9 \\
Other & 10.5 & 8.8 \\
\hline
\end{tabular}

*The percentages add to more than $100 \%$ because players were requested to provide two responses.

AFIPP, Australian football injury prevention project; PPE, personal protective equipment.

safety and previous injuries as motivators of PPE use. It is not possible to determine from this survey whether it is only a perception that the PPE in Australian football is uncomfortable, or whether this is a justifiable concern; this is worth exploring further in future studies. In particular, as reported headgear wearing rates are so low, it is difficult to understand how players were able to form an opinion that headgear was uncomfortable. It may be that the very limited evidence that headgear prevents injury in Australian football is an explanation as to why few players wear it.

This study showed that Australian football players believe that mouthguards should be worn, regardless of age, during games. In contrast, irrespective of age, they do not believe that headgear is needed during either games or training. Nonetheless, as the majority of players do not use headgear, and have indicated that their most important personal motivator to use it would be if they had an injury, it appears that the players believe that protective headgear plays a role in injury prevention. It is possible that the players' support for the use of mouthguards but not headgear could be attributed to a practice effect from junior football, which also influences their perception of comfort. Low mouthguard usage during training should be further investigated, as there is evidence that injuries do occur during this time despite the low level of PPE use. ${ }^{20} 21$

Before the use of PPE can be advocated or made mandatory in a sport, there needs to be evidence for its effectiveness and sufficient user acceptance. ${ }^{30}$ Although there is a general belief and acceptance that mouthguards are effective in preventing dental injury, ${ }^{17}{ }^{18} 211^{31-33}$ there is little evidence of the effectiveness of headgear in its current form in Australian football.

There were certain methodological limitations in our study, which we acknowledge. Using a randomised controlled trial requires a certain subpopulation to be selected and therefore limits the generalisability of the study results. The four arm design that was used in this study was randomised by group-which for this study were football teams-in an attempt to remove the potential for selection bias owing to self selection into the study and its study arms. ${ }^{34}{ }^{35}$ Despite the recruitment of teams and players from the largest community football league in Australia, the 301 players used in this study were a relatively small sample, which limits the ability to conduct complex examination on the data using multivariate analysis.

\section{Conclusions}

This study provides valuable information about the attitudes of community football players towards PPE and reasons 
Table 4 Community football players' attitudes towards protective headgear and mouthguards $(n=301)$

Strongly Neither Strongly

agree/ agree nor disagree/ Mean agreement

agree $(\%)$ disagree $(\%)$ disagree $(\%)$ score (range)

Players who wear headgear/mouthguards are less

likely to be injured than players who do not wear

headgear/mouthguards

Headgear

49.0

disagree $(\%)$ disagree $(\%)$ score (range)

Mouthguards

Headgear/mouthguards restricts a players

performance - I would rather play without it

Headgear

$\begin{array}{llll}27.4 & 39.1 & 33.5 & 3.1\end{array}$ (3.0 to 3.2)

Mouthguards

$10.2 \quad 20.1$

69.7

$3.8(3.7$ to 3.9$)$

Players who wear headgear/mouthguards can play harder than those who do not wear headgear

Headgear

$\begin{array}{llll}10.0 & 22.0 & 68.0 & 2.1(2.0 \text { to } 2.3)\end{array}$

Mouthguards

I would rather risk injury than play with protective headgear/mouthguards

Headgear

$\begin{array}{llll}21.7 & 38.1 & 40.2 & 3.3(3.2 \text { to } 3.4) \\ 7.3 & 17.5 & 75.2 & 4.0(3.9 \text { to } 4.1)\end{array}$

Experienced players do not need to wear protective headgear/mouthguards as they are not at risk of injury Headgear

Note: every player answered each question for headgear and mouthguards.

for non-use. Future research into the attitudes of community football players towards PPE should also focus more closely on previous use of PPE and whether this is a predictor of future or further use; on risk taking behaviours and their effect on PPE use; and on factors that contribute to discontinuing use while still participating in the sport. Although it seems that there are fairly consistent reasons for PPE use, perhaps further education of players, coaches, and support staff into the importance of PPE is warranted.

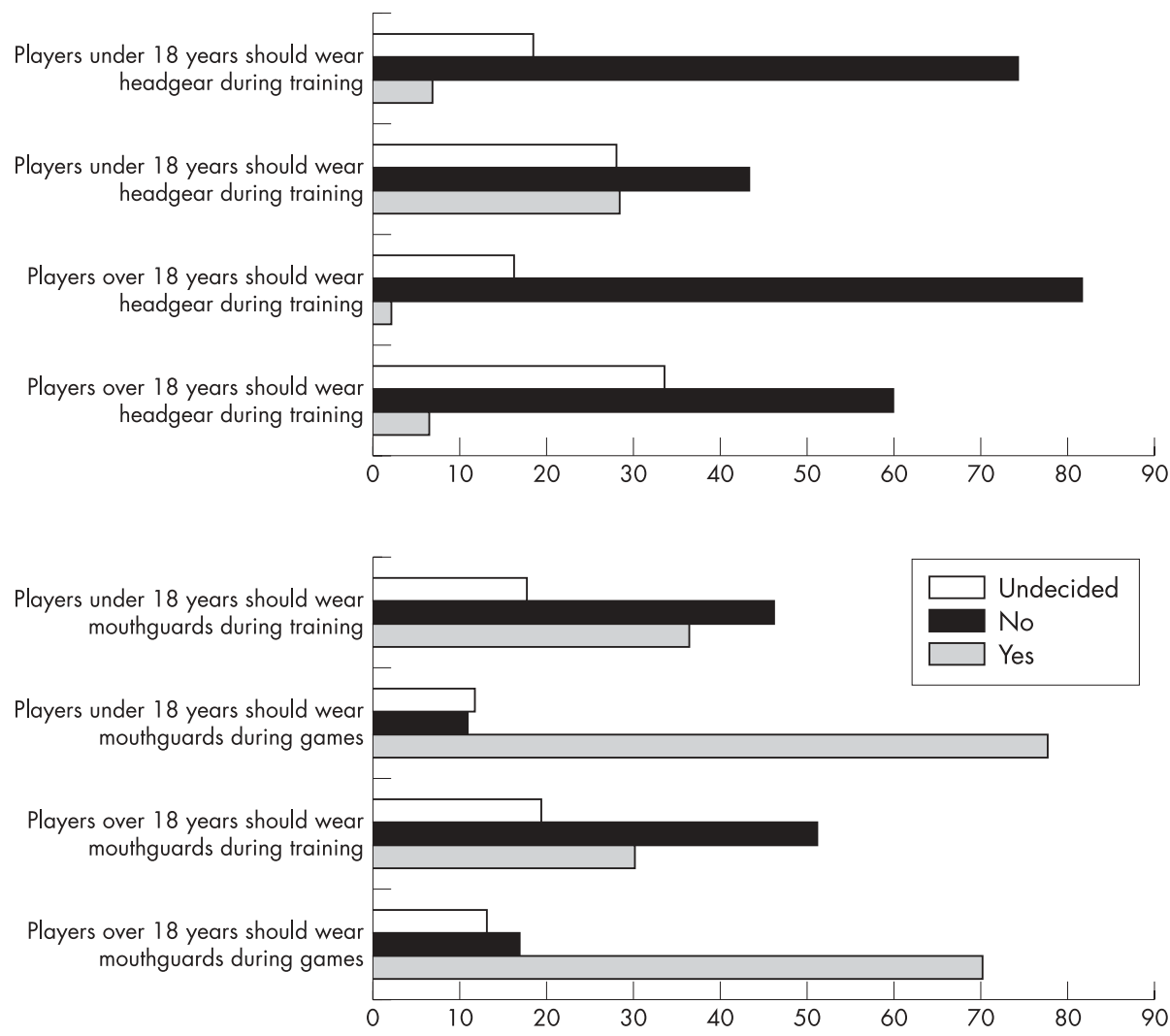

Figure 1 Players' beliefs about headgear use (above) and mouthguard use (below) during training and games. 


\section{Take home message}

Not all football players wear mouthguards and few wear headgear. Community level Australian football players generally believe that mouthguards are necessary during games but not during training, irrespective of level of competition, and that headgear is not necessary at any time.

\section{ACKNOWLEDGEMENTS}

The Australian football injury prevention project (AFIPP) is funded by the Victorian Health Promotion Foundation and supported by the Australian Football League, Football Victoria, the Victorian Smartplay Program, Sports Medicine Australia (Vic Branch), and Club Warehouse. The AFIPP chief investigators are A/Prof Caroline Finch, Ms Rebecca Braham, Dr Paul McCrory, Dr Andrew McIntosh, and Mr David Parkin. We thank the Eastern Football League and the clubs, teams, and players for their contribution to this project. RAB was supported by an NH\&MRC scholarship and a small grant provided by the Victorian Health Promotion Foundation.

\section{Authors' affiliations}

R A Braham, Department of Epidemiology and Preventive Medicine, Monash University, Clayton, Victoria, Australia

C F Finch, NSW Injury Risk Management Research Centre, University of New South Wales, Sydney, Australia

A McIntosh, School of Safety Science, University of New South Wales, Sydney, Australia

P McCrory, British Journal of Sports Medicine, Melbourne, Australia

\section{REFERENCES}

1 Cameron MH, Vulcan AP, Finch CF, et al. Mandatory bicycle helmet use following a decade of helmet promotion in Victoria, Australia - an evaluation. Accident Anal Prevent 1994;26:325-37.

2 Thompson DC, Rivara FP, Thompson R. Helmets for preventing head and facial injuries in bicyclists. Cochrane Library 2002(2).

3 Rampton J, Leach T, Therrien SA, et al. Head, neck, and facial injuries in ice hockey: the effect of protective equipment. Clin J Sports Med 1997;7:162-7.

4 Wilson B. Protective headgear in rugby union. Sports Med 1998;25:333-7.

5 Marshall SW, Waller AE, Loomis DP, et al. Use of protective equipment in a cohort of rugby players. Med Sci Sport Exerc 2001;33:2131-8.

6 McIntosh AS, McCrory P. Effectiveness of headgear in a pilot study of under 15 rugby union football. Br J Sports Med 2001;35:167-9.

$7 \mathrm{McCrory}$ P, Berkovic S, Cordner S. Deaths due to brain injury among footballers in Victoria, 1968-1999. Med J Aust 2000;172:217-19.

8 Shawdon A, Brukner P. Injury profile of amateur Australian rules footballers. Aust J Sci Med Sport 1994;26:59-61
9 Finch C, Valuri G, Ozanne-Smith J. Sport and active recreation injuries in Australia: evidence from emergency department presentations. Br J Sports Med 1998;32:220-5

10 Orchard J, Wood T, Seward H. AFL report on injuries 1998. Sydney: AFL Medical Officers Association, 1998.

11 National Health and Medical Research Council. Football injuries of the head and neck. Canberra: NHMRC, 1994.

12 Jaques T. Australian football: steps to success. South Australia: Human Kinetics, 1994.

13 Allsop R. The name of the game is Australian football. New South Wales: Aussie Sports Books, 1991.

14 Finch C, Mclntosh A, McCrory P. What is the evidence base for the use of protective headgear and mouthguards in Australian Football? SportHealth 2001:35-7.

15 Gabbe B, Finch C, Wajswelner H, et al. Australian Football: injury profile at the community level. J Sci Med Sport 2002;5:149-60.

16 Finch CF, Mclntosh AS, McCrory P. What do under 15 year old schoolboy rugby union players think about protective headgear? Br J Sports Med 2001;35:89-94.

17 Chapman PJ. Concussion in contact sports and importance of mouthguards in protection. Aust J Sci Med Sport 1985; 17:23-7

18 Chalmers D. Mouthguards. Protection for the mouth in rugby union. Sports Med 1998;25:339-49.

19 Chapman PJ, Nasser BP. Attitudes to mouthguards and prevalence of orofacial injuries in four teams competing at the second Rugby World Cup. Br J Sports Med 1993;27:197-9.

20 Banky J, McCrory P. Mouthguard use in Australian football. J Sci Med Sport 1999:2:20-9.

21 Jolly K, Messer L, Manton D. Promotion of mouthguards among amateur football players in Victoria. Aust NZ J Public Health 1996;20:630-9.

22 Williams-Avery RM, MacKinnon DP. Injuries and use of protective equipment among college in-line skaters. Accid Anal Prevent 1996;28:779-84.

23 Finch CF. Teenagers' attitudes towards bicycle helmets three years after the introduction of mandatory wearing. Injury Prevent 1996;2:126-30.

24 Eime RM, Finch CF, Sherman CA, et al. Are squash players protecting their eyes? Injury Prevent 2002;8:239-41.

25 Finch $\mathrm{C}$, Vear $\mathrm{P}$. What do adult squash players think about protective eyewear? Br J Sports Med 1998;32:155-61.

26 Finch C, Donohue S, Garnham A, et al. The safety attitudes and beliefs of elite junior Australian football players. Injury Prevention 2002;8:151-4.

27 Osberg JS, Stiles SC. Safety behaviour of in-line skaters. Injury Prevent 2000:6:229-31.

28 Maestrello CL, Mourino AP, Farrington FH. Dentists' attitudes towards mouthguard protection. Pediatr Dent 1999;21:340-6

29 Finch C, Mclntosh A, McCrory P, et al. A pilot study of the attitudes of Australian rules footballers towards protective headgear. J Sci Med Sport 2003:6:505-11.

30 Borland R, Owen N, Hill D, et al. Regulatory innovations, behaviour and health: implications of research on workplace smoking bans. Int Rev Health Psychol 1994;3:167-85

31 Blignaut JB, Carstens IL, Lombard CJ. Injuries sustained by wearers and nonwearers of mouthguards. Br J Sports Med 1987;21:5-7.

32 Petterson JA. Does rugby headgear prevent concussion? Attitudes of Canadian players and coaches. Br J Sports Med 2002;36:19-22.

33 Kerr L. Mouth guards for the prevention of injuries in contact sports. Sports Med 1986;3:415-27.

34 Murray DM. Design and analysis of group-randomized trials. New York: Oxford University Press, 1998

35 Beaglehole R, Bonita R, Kjellstrom T. Basic epidemiology. Geneva: WHO, 1993. 